\title{
The Construction of College Student Practice and Innovation Skill Network Practical Training Platform
}

\author{
Jingqing Kang \\ Shijiazhuang University of Economics \\ Shijiazhuang, China \\ e-mail: kjq2006@126.com
}

\author{
Junyin Yan \\ Shijiazhuang University of Economics \\ Shijiazhuang, China \\ e-mail:yanjy@sjzue.edu.cn
}

\begin{abstract}
The rapid development of network and information technology creates conditions for colleges to carry out student practice and cultivate innovation skill better, which makes the practical training patterns and depth expend. Based on the analysis of the actuality and feasibility of college proceeding network practical platforms taking advantage of the network and information resources, this article analyses the design discipline, overall thinking and detailed content of college student practice and innovation (P\&I) skill cultivation schemes. Meanwhile, it plans and designs student P\&I skill practical training platform system in the big picture, proposing practical suggestions and solutions to related issues in the construction and operation of the network practical training network.
\end{abstract}

Keywords: college, network and information, practice and innovation skill, network practical training platform

\section{INTRODUCTION}

The two principal features of the nowadays society are network and information. In the environment of fierce market competition, He could occupy initiative in the competition whoever gets more and newer information taking fully advantage of network resource. With the extension of admission of the colleges nowadays, there has been a general education resources shortage condition such as the dormitories, experimental resources and library resources. Under this condition, it becomes a project with significant research meaning to research how to construct intellectual cultivation network practical training platforms, search new paths and patterns of college information service in network conditions, taking fully advantage of college network and information resources, to strengthen the service function in college intellectual cultivation aspect, improve the density of knowledge, information and function.

\section{THE ACTUALITY AND FEASIBILITY OF THE CONSTRUCTION OF NETWORK PRACTICAL TRAINING PLATFORMS}

The current conditions of college education propose realistic need to network practical training platforms. First of all, our country established and proceeded the college education system reforming thinking of " co-construction, adjusting, cooperation and merging" in succession since 1990s. Among which merging is the combination among related colleges adjusting measures to local conditions to improve education quality and school effectiveness and bring complementary among subjects and the scale benefit into reality. According to "College Mergers Since 1990 ” from China Upgrade Education Student Information Network, since the document delivered on 12-Jan-1990 about merging Xi' an Union University from the Ministry of Education, there have been mergers associating more than 1000 colleges and integrated them into 400 plus colleges[1]. College merger makes it a widespread phenomenon among colleges to put multi-campus pattern of education into practice. Module, which important academic meeting and publishing scholarly determines traditional entity practical training facility construction no longer adjusts realistic need. In other words, taking fully advantage of network superiority to carry out network practical training construction has evident realistic meaning. Secondly, with the enrichment and development of college education gradation and education patterns, it has been one of the most important ways of college intellectual training to proceed correspondence education and TV university education and remote education with open style education as the main part, and realizing remote education and experimental practical training through network environment becomes realistic need. Besides, a new round of college education system reform brings a new situation of college leapfrog development as well. Ever since college admission extension since 1999, the admission amount has increased with ladder shape year by year from 1.64 million in 1999 to 6 million in 2009. It has been a widespread phenomenon for each college to face the shortage of campus area, experiment sites and facilities. Total dependence of denotative expansion with new campus construction is neither good for the macroscopic investment control of the country, nor good for colleges' survival and development under huge amount of debt. On the contrary, it' $s$ the realistic choice for colleges to construct virtual experimental practical training platform in network condition and improve the knowledge content, information content and function value within unit campus area [1].

Meanwhile, the excellent education resources and condition of colleges offer realistic feasibility for the construction of network practical training platforms. Firstly, the external network, campus network and all kinds of other local area network make up plentiful network system in the colleges, which creates condition for the college virtual lab construction. Secondly, the continuously improving information and knowledge service function lays a solid foundation for the realization of network functions of 
practical training platform related information, data' $\mathrm{s}$ collection, storage, integration enrichment and update. Thirdly, the universality of computers and network within students offers probability to the construction and operation of campus network practical training system, thus getting avoided of the shortage of entity lab resources and the limitation of open time, providing convenience for students to precede practical training activities anytime. In a word, college network practical training platform construction is both realistic need and with feasibility.

\section{THE COMPOSITION OF STUDENT PRACTICE AND INNOVATION SKILL TRAINING SCHEME}

Practice and innovation skills are important components in the course of college intellectual training; it' $s$ also the key to precede student skill and qualification education. There' re four principles to insist on in the process of practice and innovation skill training scheme design as follows. The first is tight combination with course education plan principle, the second is overall systematic ness principle, the third is consistence principle, and the fourth is the principle of combination between concentration and discrete. Based on principles above, the overall thinking of college student practice and innovation skill cultivation scheme design has been settled, i.e. Aimed at cultivating applicable intellectuals with both practice and innovation skills, determining practical teaching content with both foundational and comprehensive practice, both foundational skill training and innovation, to meet the harmonious development requirement of students' knowledge, skill and qualification[2]. Based on the principle and overall thinking above, we can determine the overall frame of practical teaching training scheme shown as figure 1.

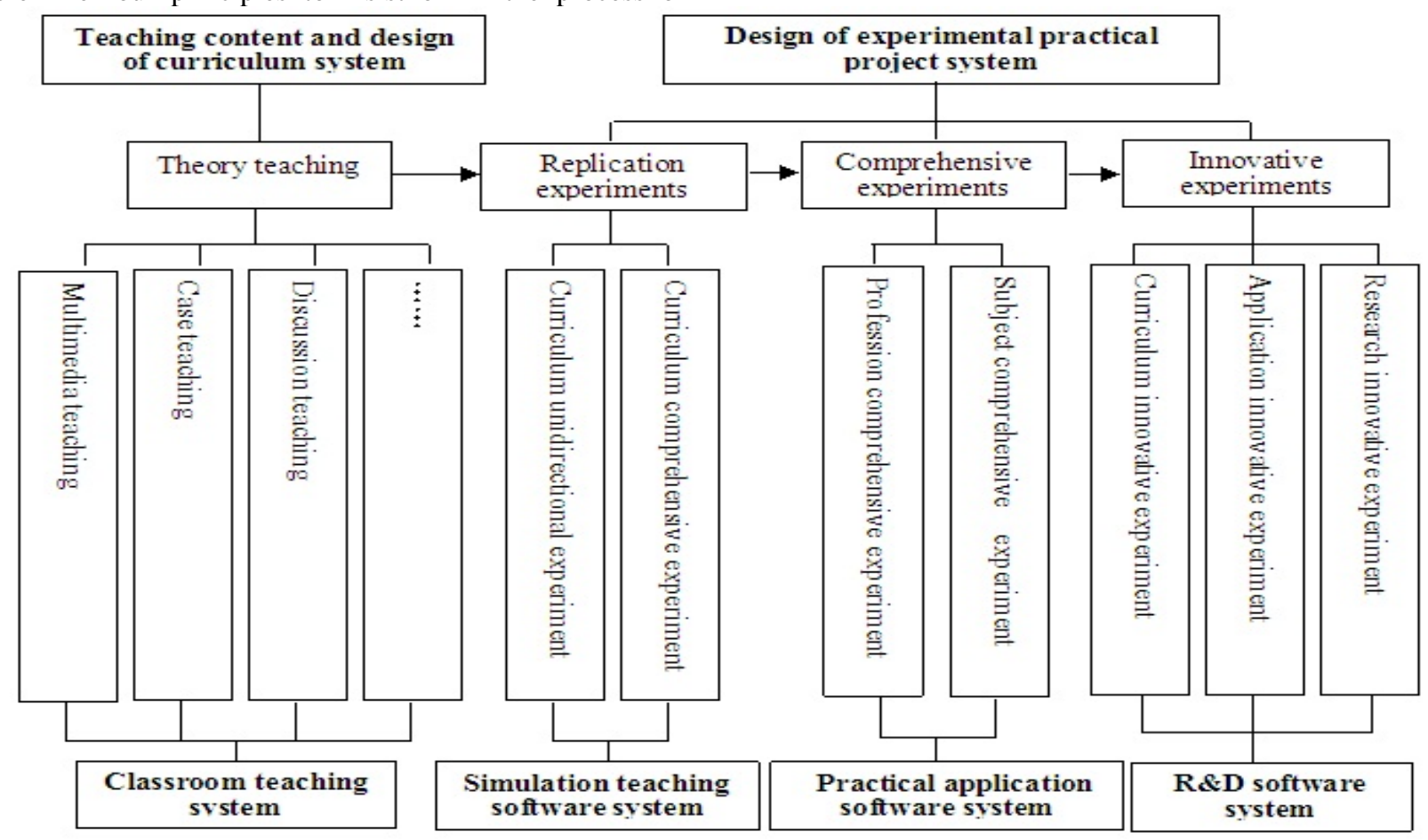

Figure 1. design frame of practice and innovation skill cultivation scheme

As we can see from the picture, it' s a entire intellectual cultivation and training systematically realizing process from the students entering the colleges to their final graduation as qualified intellectual. During this process, the key is the theory education, practice education and innovation skill cultivation associated to a certain subject or major. The key point of theory education includes course system design, education content update, and the reform of education pattern and idea, which compose class education system of theory knowledge. Practice education proceeds as the theory education goes, with theory knowledge test experiments (including single course and comprehensive test experiments), subject professional knowledge comprehensive experiments (including professional knowledge and subject knowledge comprehensive experiments), professional skill and qualification innovation experiments (including course knowledge, practical application and science research innovation experiments). Different experiments bear the missions from knowledge, skills and comprehensive qualification. And aimed at different purposes and requirements of different experiment teaching proceeding, different experiment system and environment would be configured accordingly. Propose of theory knowledge test experiments are to deepen the comprehension to associated professional knowledge. Thus the simulating teaching software system tightly associated with teaching content would be chosen. The aim of subject professional knowledge comprehensive experiments is to 
make students understand and master professional knowledge overall, and cultivate their practical work skills, so the applicable software system associated with social economic activities shall be chosen. When it comes to upgrade professional skills and qualification experiments, their aim is to cultivate students' development skills and innovation skills, so the applicable research development software system shall associate detailed subjects [2].

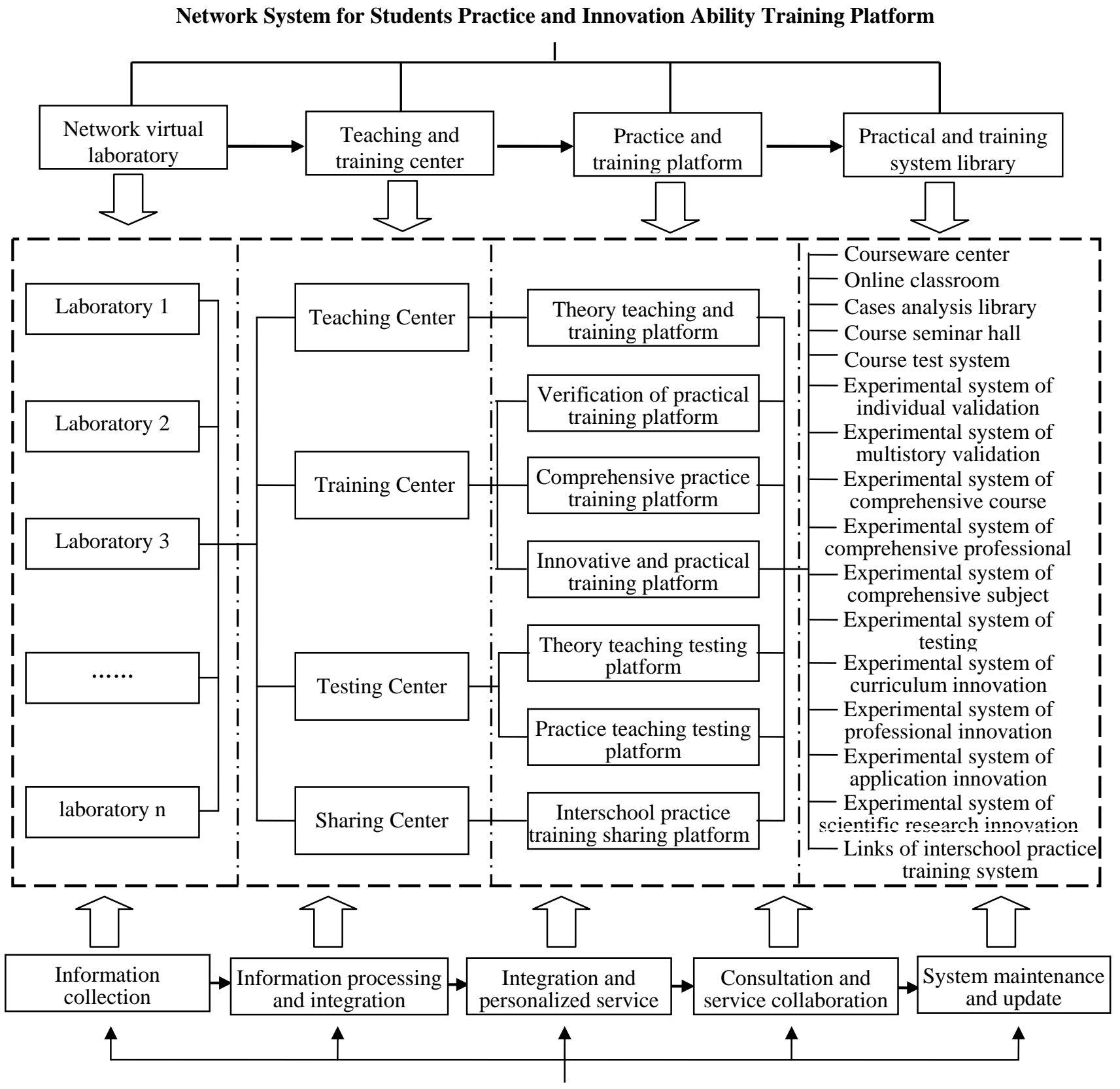

Network Information Security System

Figure 2. frame of practice and innovation skill practical training platform system 


\section{PRACTICE AND INNOVATION SKILL PRACTICAL TRAINING SYSTEM DESIGN IN NETWORK CONDITION}

Based on student practice and innovation skill cultivation scheme system' s contents and requirements above, the student practice and innovation skill network practical training platform system has been constructed taking fully advantage of the superiority colleges master in aspects such as external and internal network resources collection, arrangement, processing, integration, reference, consultancy and coordination as Picture 2. This system composes of following 5 components. (A) Network labs. Several virtual network labs could be designed based on users scale. Each lab could be classified based on experiment content and requirement. Students carry out experiment practical training activities in different aspects in different network labs. (B) Teaching and practical training center. This center is divided into teaching center, practical training center, test center and share center according to different functions. Among them, teaching center is mainly to meet course theory teaching need. Practical training center is to precede different kinds of experiments and practical trainings. Test center is mainly to the test and evaluation of theory and practice teaching effect. Share center could be shared within different colleges, so as to explore external practical training resources. (C) Practical training platforms. Based on the teaching and practical center function division above, there have been establishments in succession of theory teaching practical training platform, test practical training platform, comprehensive practical training platform, innovative practical training platform, theory teaching test platform, practical teaching test platform and inter-college sharing practical training platform. Modularity of different practical training contents and functions could be realized through those platforms. (D) Practical training system library. Dedicated system libraries have been established according to different aspects such as theory teaching, practice, test, innovative skill cultivation, and inter-college platform links, so as to meet different need of function realization. Of course, this system library could be designed according to indeed need by different colleges subjects and majors. For example, successful innovative sample reference system, innovative subject analysis design system and innovative subject resource data reference system and innovative subject online coach system could be added into this library. $€$ Library network information insurance system. This system is composed of functions of information collection and storage, information arrangement, information integration and individual service, information reference consultancy and service cooperation, system maintenance and update, so as to take fully advantage of library network information superiority to guarantee the systematical analysis and design of the practical training system, data library construction, system links, system maintenance and update, etc [3], [4].

\section{TRAINING PLATFORM CONSTRUCTION AND ATTENTION SHOULD BE PAID TO THE PROBLEMS DURING THE OPERATION}

First, must pay more attention to develop advantageous characteristically and basic disciplines training platform. Universities and colleges include many subjects and professions. The research design development of the training platform for students to practice and develop innovation ability, which can not be fully carried out in all subjects and professions, We must be combined with advantages and characteristics of the school, combined with the training content application field and range of different subjects and professions. Then we priority select the subjects and professions which have advantages, wide application and basic to construct and operate [5].

Second, through the university interscholastic league realize the sharing of resources, in every school select advantages and characteristics subjects and professions to develop and construct student's practice and innovation ability training platform. Through the university interscholastic league, open the network link between the laboratories. Such as the establishment of national, provincial excellent course network training platform system link, realize the sharing of resources, expand the application scale and scope of each school network training platform, improve the utilization rate of the training platform. So that making the training platform construction work can get twice the result with half the effort.

Third, pay attention to division and cooperation of various departments. The planning, design, development, construction and operation network training platform is a complicated system engineering, Which is needed joint action through the school network center, experiment and practice center, departments, modern educational technology center and other relevant departments. They division of cooperation separately from the system planning, analysis and design, collection and integration of network information resources, plan of training professional talent person, determination of the content of training system of practice and innovation ability, technical support of platform system design and development etc. In order to ensure the training platform construct and operate smoothly.

Fourth, pay attention to enrich, update and improve information of training platform system. The implementation and operation of the students practice and innovation ability training platform is a dynamic construction process. It needs revise, enrich, update and improve its structure and content constantly with the change of time and objective situation. To ensure the system' $\mathrm{s}$ suitability and sustainability, realize the system update and upgrade constantly, meet the development of the students practice and training teaching activities in the school.

\section{ACKNOWLEDGMENT}

Foundation item: Hebei Province Social Sciences Fund project in 2012 (201203207) 


\section{REFERENCES}

[1] Hu Lin. Study on the construction of information resources of the multi-campus university library[D].Chengdu, Sichuan University, 2006:3-7

[2] Yan Junyin, Kang Jingqing. Plan and design of teaching plan of professional practice management in colleges and universities[J]. Shijiazhuang, Journal of Shijiazhuang University of Economics, 2007(6):124-127
[3] Zhou Jingzhi, Zhang Xiaoqing. A comparative study of digital information service system[M]. Beijing, Science Press, 2009: 163166

[4] Chen Ya. Knowledge library: Theory and model[M]. Nanjing, Nanjing University Press, 2008:315-331

[5] Yan Junyin, Zhang Jugang, Liu Cuie. Exploring about reform and development of talents cultivation in academies of geology[J]. Beijing, Chinese Geological Education, 2009(4):64-69 